Encontros Bibli: revista eletrônica de biblioteconomia e ciência da informação, $v .17, n$. esp. 2 - III SBCC, p.55-64, 2012. ISSN 1518-2924. DOI:10.5007/15182924.2012v17nesp $2 p 55$

\title{
ACESSO ABERTO À INFORMAÇÃO CIENTÍFICA E DIREITO AUTORAL: AÇÕES E CONTRADIÇÕES
}

\author{
Maria Naires Alves de Souza ${ }^{\mathrm{i}}$ \\ Denyse Maria Borges Paes ${ }^{\text {ii }}$ \\ Rafael Gomes Fernandes iii \\ Francisco Welton Silva Rios ${ }^{\text {iv }}$
}

Resumo: Aborda a questão do acesso aberto à informação científica, na sociedade atual, e as restrições impostas pelos ordenamentos jurídicos que defendem a propriedade intelectual. Objetiva-se, analisar a dissonância entre o Direito Autoral e o acesso aberto à informação científica com o fim de identificar suas ações e contradições. Trata de uma pesquisa bibliográfica e documental seguida de leituras e discussões em grupo. Evidenciou-se que o Direito Autoral brasileiro resguarda o autor ou titular (editoras) em prejuízo ao acesso aberto à produção científica financiada com recursos públicos. Verificou-se uma diversidade de iniciativas em vários países em prol do acesso aberto.

Palavras-chave: Informação científica. Direito autoral. Acesso aberto. Universidade. Direito à informação.

\section{OPEN ACCESS TO SCIENTIFIC INFORMATION AND COPYRIGHT: ACTIONS AND CONTRADICTIONS}

\begin{abstract}
This article addresses the question of open access to scientific information in contemporary society and the restrictions imposed by laws that defend intellectual property. The purpose is to analyze the disagreement between the Copyright and open access to scientific information in order to identify their actions and contradictions. This is a bibliographical research and documental followed by readings and group discussions. It was evident that the Brazilian Copyright Law protects the author or owner (publishers) in damage to open access to scientific production financed with public funds. It was verified a diversity of initiatives in several countries in favor of open access.
\end{abstract}

Keywords: Scientific information. Copyright. Open access. University. Right to information.

\footnotetext{
${ }^{\mathrm{i}}$ Universidade Federal do Ceará. marianaires@yahoo.com.br

${ }^{\text {ii }}$ Secretaria de Educação do Município de Fortaleza. denyse mb@yahoo.com.br

iii Universidade Federal do Ceará. rafael@dee.ufc.br

iv Universidade Estadual do Ceará. welsilrio@yahoo.com.br 


\section{INTRODUÇÃO}

O conhecimento científico é o tipo de conhecimento produzido pela investigação científica, mediante métodos, além de ser passível de verificação; é gerado com a finalidade de promover soluções para as questões do homem e do meio em que este habita, como também para oferecer explicações sistemáticas que possam ser testadas e verificadas. Para que esse conhecimento cause transformações em ambientes técnico-científicos e sociais é imprescindível que ele seja acessível à comunidade científica e para aqueles que se interessam em estudá-lo.

Entretanto, quando esse conhecimento é gerado dentro das universidades públicas e, portanto, com recursos públicos, ele deveria também ter o caráter público para seu acesso. Idealmente, a informação científica deveria ser acessível a qualquer indivíduo (pesquisador, estudioso, estudante, leigo), contudo, sua disponibilização vem se deparando com os limites colocados pelos direitos dos autores, que impõem condições monetárias, entre outras, dificultando seu uso e acesso. Frente a essa problemática, buscou-se informações a respeito do tema e percebeu-se o prejuízo que a falta de acesso aberto à produção científica tem provocado na produção do conhecimento científico e impactado nos estudos e nas pesquisas realizadas e, consequentemente, nos acervos disponíveis para pesquisas nas bibliotecas universitárias públicas.

Ante os problemas abordados, este artigo tem como objetivo analisar a dissonância entre o Direito Autoral e o acesso à produção científica com o fim de identificar suas ações e contradições.

\section{MATERIAIS E MÉTODOS}

Esta é uma pesquisa do tipo bibliográfica e documental, que segundo Polit, Beck e Hungler (2008), desenvolve-se a partir de materiais já elaborados, pelos quais o pesquisador pode fazer uma cobertura mais ampla dos fenômenos investigados. A finalidade do estudo é colocar o investigador em contato direto com publicações produzidas e debatidas acerca de um determinado conteúdo, ressaltando que estas não se tratam de uma repetição do que já foi dito ou escrito sobre certo assunto, mas do exame de um tema com um novo enfoque (LAKATOS; MARCONI, 2008). 
Para obtenção dos dados e informações, realizou-se um levantamento bibliográfico e documental em livros e portais de acesso aberto: Scientific Electronic Library Online (Scielo), Portal de Periódicos da Coordenação de Aperfeiçoamento de Pessoal de Ensino Superior (CAPES) e Biblioteca Digital Jurídica (BDJur). A partir do levantamento das informações, encontrou-se artigos científicos, documentos legais, folhetos, trabalhos apresentados em eventos, dos quais se procedeu leituras e análise, seguidas de discussões em grupo para definição e construção dos argumentos.

\section{UNIVERSIDADE}

A informação é um instrumento inerente a nossa vida. Desde muito cedo somos induzidos a utilizá-la, mesmo quando não conseguimos reconhecer o seu significado, por vezes, subjetivo. Atualmente, na sociedade caracterizada como do conhecimento, a informação torna-se fator de fundamental importância. Segundo Takahashi (2000, p. 5),

\footnotetext{
A informação representa uma profunda mudança na organização da sociedade e da economia, havendo quem considere um novo paradigma técnico-científico. É um fenômeno global com elevado potencial transformando as atividades sociais e econômicas $[\ldots]$.
}

Evidencia-se, portanto, a necessidade de tornar pública a informação gerada, uma vez que esta poderá servir de subsídio para criação de novos conhecimentos. Nesse contexto, destaca-se um novo cenário, onde as tecnologias da informação e da comunicação potencializam o processo de produção e comunicação, permitindo maior interação entre o produtor e consumidor.

Assim, as universidades podem ser entendidas como facilitadoras da comunicação entre seus estudantes, professores e a sociedade, validando seu tripé ensino, pesquisa e extensão ao promover a disseminação do conhecimento científico e das pesquisas em andamento ou concluídas, assegurando ao público o direito de acesso às informações. 


\section{BIBLIOTECA UNIVERSITÁRIA}

O conhecimento gerado na universidade possui seus próprios meios de divulgação formais e informais, bem como agentes que permitem a ratificação deste como conhecimento científico.

Toda a produção científica é registrada e difundida por meio de documentos. Nesse sentido, a biblioteca universitária emerge enquanto mediadora desse processo, pois armazena e organiza o conhecimento visando otimizar a recuperação e sobretudo o acesso a este, já que "a exigência de informação transcende o valor, o lugar e a forma e necessita de acesso. Por isso devemos pensar não só em fornecer a informação, mas possibilitar o acesso simultâneo de todos" (FUJITA, 2005, p. 4).

Nos dias atuais, os sistemas de informação, contextualizados no fenômeno da globalização, vêm se modificando. São disponibilizados documentos não somente no formato impresso, mas também digital, já que este propicia o acesso rápido e multiusuário.

Conforme Cunha (2008), a biblioteca universitária, no momento em que disponibiliza, além de seu acervo físico, um acervo digital, permite maior eficácia na busca, acesso e recuperação da informação, quesitos que tem atraído cada vez mais usuários a essas bibliotecas.

A informação, principal insumo da universidade, estará mais acessível aos docentes e pesquisadores através da biblioteca digital, já que esta transpõe as barreiras físicas e permite que muitos usuários consultem um ou vários trabalhos simultaneamente (FUJITA, 2005).

\section{DIREITO AUTORAL E UNIVERSIDADE PÚBLICA}

Passaremos agora, a uma rápida reconstrução e análise do surgimento do Direito Autoral e do impacto deste sobre a produção de conhecimento nas Universidades Públicas.

Cabe-nos, de início, alguma introdução sobre o fenômeno da autoria que deve ser analisado levando-se em conta os vários macrofatores que sobre ele exercem influência, sejam estes sociais, econômicos, políticos, ou técnicos. Para Chartier (1999), tal fenômeno teve início na Europa, durante a Idade Média, quando, sob acusação de heresia, inúmeros 
documentos foram destruídos pelas autoridades religiosas e políticas que, com o intuito de punir os transgressores, tinham antes que designá-los como autores das obras censuradas. Foucault (1992, p. 47) complementa, argumentando que a autoria surgiu "na medida em que o autor se tornou passível de ser punido, isto é, na medida em que os discursos se tornaram transgressores." A regra, no entanto, era o anonimato das obras.

A partir do século XIV, o Renascimento, com valores forjados no antropocentrismo e individualismo, induziu a valorização da produção intelectual humana, como a arte e a ciência. Foi o momento histórico propício para o reconhecimento da autoria, o qual foi intensificado pela invenção da tecnologia de impressão por Johann Gutenberg (1398 - 1468). Os materiais escritos passaram a ser produzidos em ritmo crescente e os autores tiveram a oportunidade de assinarem suas obras, ganhando, a partir daí, personalidade ligada à produção. Não demorou até o surgimento do mercado gráfico e dos editores, proprietários do maquinário de imprensa e responsáveis pela distribuição da nova mercadoria, os quais, em 1557, obtiveram do governo inglês o direito exclusivo e eterno sobre as obras (ARAYA; VIDOTTI, 2009).

Em 1710, a primeira lei formal sobre o Direito Autoral foi promulgada na Inglaterra, o Statute of Anne, que tirou o direito sobre a obra dos editores passando-os aos autores. Em 1790 foi instituída, nos Estados Unidos, a primeira lei copyright (ARAYA; VIDOTTI, 2009).

No Brasil, em 11 de agosto de 1827, surgiu a primeira lei sobre o direito do autor que, além de criar os cursos jurídicos nas cidades de Olinda e São Paulo, determinou privilégio exclusivo pelo período de 10 anos à produção acadêmica dos professores sob determinadas condições relacionadas na própria lei. A Constituição Brasileira, porém, apenas em 1891 discorreu sobre o tema, em seu Título IV - Dos cidadãos brasileiros, Seção II - Declaração de direitos, art. 72, § 26, a qual declarava que “Aos autores de obras literárias e artísticas é garantido o direito exclusivo de reproduzi-las, pela imprensa ou por qualquer outro processo mecânico. Os herdeiros dos autores gozarão desse direito pelo tempo que a lei determinar." (BRASIL, 1891). A atual Constituição Brasileira, de 1988, mantém, quase nos mesmos termos da Constituição de 1891, a proteção aos direitos do autor. Atualmente, a Lei 9.610 de 19 de fevereiro de 1998 (BRASIL, 1998) disciplina o tema.

A lei autoral brasileira, com suas inúmeras limitações e restrições ao uso da propriedade intelectual, é tida como uma das mais rígidas do mundo, impondo sólidas barreiras ao acesso a diversos tipos de informações científico-culturais (LIMA; SANTINI, 2008; PARANAGUÁ; BRANCO, 2009). De acordo com a legislação, cabe exclusivamente 59 
ao autor o direito de utilizar, fruir e dispor da obra, o qual tem a prerrogativa de ceder totalmente ou parcialmente seus direitos a terceiros (BRASIL, 1998).

Sem nos atermos demasiadamente a tecnicismos e exegeses jurídicas, visto não ser o objetivo do presente estudo, passaremos a analisar alguns impactos do Direito Autoral na produção e disseminação do conhecimento científico produzido em Universidades Públicas brasileiras. Cabe-nos levantar a discussão em torno do acesso ao conhecimento produzido com recursos públicos.

No Brasil, atualmente, os recursos públicos são os principais responsáveis pelo financiamento da pesquisa científica. Tal financiamento realiza-se por meio do pagamento de funcionários docentes e não docentes, da infraestrutura universitária, da provisão de equipamentos laboratoriais e recursos diretos para projetos e bolsas de estudos (CRAVEIRO; MACHADO; ORTELLADO, 2010).

A CAPES é a agência governamental brasileira responsável pela avaliação da pósgraduação nacional stricto sensu e pelo acesso e divulgação da produção científica, entre outras incumbências ${ }^{5}$. Ela, ao avaliar os Programas de Pós-Graduações nacionais, utiliza como principal índice de avaliação a quantidade de publicações de artigos em revistas qualificadas. Atualmente, os artigos científicos são o meio mais eficiente de divulgação do conhecimento científico, deixando a comunidade científica rapidamente a par de métodos, referenciais teóricos e resultados (BARBA, 2012). No entanto, após a produção e publicação de pesquisas financiadas com verba pública, surgem diversas barreiras para o acesso a estas por parte da comunidade acadêmica.

Ao publicar em periódicos científicos, o autor do artigo/pesquisa cede seus direitos autorais ao editor que, geralmente, condiciona o acesso à informação à assinatura do periódico ou ao pagamento direto de certa quantia que pode variar de acordo com a excelência da informação solicitada. Somada a essa equação, conforme apontam Craveiro, Machado e Ortellado (2010), ocorre à ação oligopólica de conglomerados editoriais que, ao se apropriarem de editoras menores, buscam o controle da informação científica. Os autores apontam sobre as editoras: "Para se ter uma ideia da concentração, a Reed Elsevier, por exemplo, afirma possuir 12.500 periódicos científicos em seu catálogo, a Thomson outras 8.500 e a Springer Verlag, 1.800." (CRAVEIRO; MACHADO; ORTELLADO, 2010, p. 15).

Não existe, no Brasil, políticas que limitem a apropriação pelas editoras dos conhecimentos científicos gerados com financiamento público. Mesmo após todos os recursos

\footnotetext{
${ }^{5}$ Dados disponíveis no site da CAPES: http://www.periodicos.capes.gov.br
} 
investidos na produção do conhecimento, o Estado acaba por pagar novamente pelo seu acesso. No ano de 2010, a União investiu na aquisição de periódicos o valor aproximado, em dólar, de US\$ 61.180.065,00 ${ }^{6}$.

\title{
6 CONSIDERAÇÕES FINAIS
}

Acompanhando o tratamento das informações arquivísticas referentes ao registro e às alterações de projetos lançadas no SIE e, também, com base nos depoimentos dos entrevistados, constatou-se uma situação bastante atípica em relação aos requisitos que viabilizam e sustentam a autenticidade e a fidedignidade dos documentos, deduzindo-se que o sistema pode estar comprometido em relação a essas duas características. Corroboram essa afirmação as seguintes constatações: $1^{\circ}$ ) há debilidade/falta de controle oficial de grupos, categorias e/ou níveis de acesso ao sistema; $2^{\circ}$ ) há indisponibilidade do registro do histórico das intervenções ou alterações de informações arquivísticas no sistema, ausência de trilha de auditoria. Para haver conformidade com esse aspecto, teriam que ser observados estudos do ICA16 (2005) e aplicada a norma ISO 15489-2 bem como os seguintes requisitos descritos no e-ARQ Brasil:

\begin{abstract}
$\mathrm{O}$ rastreamento dos documentos em trilhas de auditoria é uma medida de segurança que tem por objetivo verificar a ocorrência de acesso e uso indevidos aos documentos. O grau de controle de acesso e o detalhamento do registro na trilha de auditoria dependem da natureza do órgão ou entidade e dos documentos produzidos (CONArq, 2006, p.36).
\end{abstract}

Portanto, quanto aos critérios que asseguram idoneidade aos documentos, segundo Rondinelli (2005), Rocha (2007) e também Ferreira (2006), acredita-se que o SIE apresenta-se seriamente comprometido.

Através do acompanhamento do gerenciamento das autorizações de acesso ao sistema, observou-se que esse gerenciamento é realizado de maneira informal pelo serviço de auxílio ao usuário, denominado CAU, que é operado por bolsistas e que, na operação desse sistema, não existe nenhum tipo de protocolo ou registro de solicitação de ativação ou desativação de autorizações de senhas para acesso ao mesmo. Também, conforme depoimento dos entrevistados, a fragilidade $\mathrm{e}$ as deficiências do gerenciamento de senhas são percebidas e referem-se a situações em que as pessoas já

\footnotetext{
${ }^{6}$ Dados disponíveis no site da CAPES: http://www.periodicos.capes.gov.br

${ }^{5} \mathrm{http}: / /$ www.tavanir.org.ir/tech-doc/nezam/iso_15489-2.pdf 61 
não ocupam cargos de chefia e, apesar disso, continuam com a sua senha autorizada para tramitar documentos na condição de responsáveis pela subunidade.

Outra situação citada pelos entrevistados é a falta de normatização na definição de grupos de usuários e suas respectivas funções hierárquicas no sistema, ou seja, maior clareza sobre os tipos de funções e autorizações que lhes são pertinentes. Considerando o que afirmam Santos (2005), Innarelli (2009) e CONArq (2006) quando se trata de normas de segurança para o controle do acesso ao sistema:

\begin{abstract}
Um sistema de gestão arquivística de documentos deve garantir que os usuários não autorizados não tenham acesso aos documentos classificados, isto é, submetidos às categorias de sigilo previstas em lei, bem como aqueles que são originalmente sigilosos. O acesso aos metadados dos documentos sigilosos depende de regulamentação interna do órgão ou entidade. (CONArq, 2006, p.35)
\end{abstract}

Em relação às autorizações de acesso ao sistema, pode-se afirmar que, pelo fato de as portarias serem gerenciadas por essa ferramenta de gestão, elas respaldariam automaticamente os acessos ao sistema.

No tocante ao processo de interação dos usuários com o sistema, inicialmente considerou-se a questão do manual de registro e alterações de projetos. Quanto a esse aspecto, a situação mostra-se insólita, uma vez que, segundo informações fornecidas pelos entrevistados responsáveis pelo gerenciamento do sistema e acesso à página da UFSM, o manual de registro de projetos não é disponibilizado aos usuários no sistema (SIE), e sim no site da instituição, que está desatualizado. Isso ocorre em razão das frequentes modificações/alterações nas rotinas de tela e a outras questões congêneres que são feitas pelo CPD para atender situações específicas, de forma a sanar dificuldades encontradas por parte de um determinado usuário. Nesse sentido, cita-se o Manual de Certificação para Sistemas de Registro de Eletrônico em Saúde, que estabelece regras rígidas em relação a manuais. O problema verificado está na falta de divulgação dessas alterações para os demais usuários, os quais encontram as mesmas dificuldades na operacionalização do sistema. Em relação a esse problema, recorre-se, mais uma vez, aos estudos do ICA16 (2005) ao afirmar que:

Ao mesmo tempo devem ter em conta as actualizações da documentação do sistema porque muitas das correções nele realizadas podem ter sido feitas em situações de emergência, altura em que não sobre tempo para elaborar documentação apropriada sobre as alterações introduzidas (ICA 16, 2005 p.37).

Quando se refere ao desafio de se manter um banco de dados íntegro em relação aos quesitos que dizem respeito às normas e à legislação arquivísticas vigente, cita-se Rocha e Silva (2007, p. 116): “O grande desafio apresentado pelos documentos digitais 
é a garantia da produção de documentos confiáveis e a manutenção de sua autenticidade e acesso de longo prazo".

Portanto, faz-se necessário que sejam mantidas adequadamente as informações arquivísticas constantes dos registros dos projetos e armazenadas no banco de dados da UFSM, o qual se constitui como patrimônio documental da instituição, já que a prática institucional é registrar projetos. Tal prática acontece há aproximadamente 25 anos através do sistema, e é estimulada pela administração Central, que considera o compromisso institucional que envolve o Ensino, a Pesquisa e a Extensão. Essa manutenção adequada também é necessária devido às implicações orçamentárias e administrativas na instituição, assim como no âmbito do MEC. O registro do que do foi, do que é e do está planejado para ser desenvolvido na instituição no que se refere ao Ensino, à Pesquisa e à Extensão está nesse sistema. Por esses motivos é que os dirigentes da instituição e seus usuários devem zelar para que esse sistema seja dotado de garantias que viabilizem a fidedignidade e a autenticidade das informações arquivísticas armazenadas no sistema, e garantam acessibilidade à sociedade e a meio acadêmico, ressaltando-se que o banco de projetos da instituição também é considerado como patrimônio documental, amparando-se no que diz a Constituição Federal de 1988, em seu artigo 216:

Constituem patrimônio cultural brasileiro os bens de natureza material e imaterial, tomados individualmente ou em conjunto, portadores de referência à identidade, à ação, à memória dos diferentes grupos formadores da sociedade brasileira, nos quais se incluem: I -as formas de expressão; II -os modos de criar, fazer e viver; III -as criações científicas, artísticas e tecnológicas; IV - as obras, objetos, documentos, edificações e demais espaços destinados às manifestações artístico culturais; V -os conjuntos urbanos e sítios de valor histórico, paisagístico, artístico, arqueológico, paleontológico, ecológico e científico (CONSTITUIÇÃO DA REPÚBLICA FEDERATIVA DO BRASIL, 1988).

Desse modo, espera-se que as considerações aqui apresentadas possam servir de subsídio para que os administradores do sistema possam proceder a algumas modificações que julgarem necessárias para torná-lo mais eficiente. 


\section{REFERÊNCIAS}

ACEVES, M. R. La archivística: ¿ciencia o técnica?. In: ROJAS, Miguel Angel Rendón (coord). Bibliotecología, archivística, documentación: intradisciplina, interdisciplina o transdisciplinariedad [et al.]. - México: Centro Universitário de Investigaciones Bibliotecológicas, 2011. p. 39-49.

Bellotto, H. L. Arquivos permanentes: tratamento documental. 4. ed. rev. ampl. Rio de Janeiro: FGV, 2007.

CONARQ, Conselho Nacional de Arquivos; Câmara Técnica de Documentos Eletrônicos. Modelo de requisitos para sistemas informatizados de gestão arquivística de documentos: e-ARQ Brasil. 2006. Disponível em: $<$ http://www.conarq.arquivonacional.gov.br/Media/publicacoes/earqbrasilv1.pdf $>$. Acesso em: 08 out. 2008.

FERREIRA, M. Introdução à preservação digital: conceitos, estratégias e actuais consensos. Guimarães, Portugal: Escola de Engenharia da Universidade de Minho, 2006.

INTERNATIONAL COUNCIL ON ARCHIVES. Committee on current records in a electronic environment. Electronic records: workbook for archivist. Paris (France): ICA, 2005. (ICA Studies 16). Disponível em:

$<$ http://www.ica.org/10801/studies-and-case-studies/ica-study-n16-electronic-records-aworkbook-for-archivists.html>. Acesso em: 08 out. 2008.

INNARELLI, H. C. Preservação digital e seus dez mandamentos. In: SANTOS, Vanderlei Barbosa dos (org). Arquivística: temas contemporâneos. Brasília: SENACDF, 2007. p. 21-71.

LOPES, L. C. A nova arquivística na modernização administrativa. Rio de Janeiro : [s. n.], 2000. 369 p.

MOREQ. Especificação Moreq. Modelo de Requisitos para a Gestão de Arquivos Eletrônicos. Bruxelles - Luxembourg, [s. n.] 2001. Disponível em: http://europa.eu.int/idabc/servlets/Doc?id=16849. Acesso em: 08 out. 2008.

ROCHA, Cláudia Lacombe; SILVA, Margareth da. Padrões para Garantir a Preservação e o Acesso aos Documentos Digitais. Acervo, Rio de Janeiro, v. 20, n. 1-2, p. 113-124, jan./dez. 2007.

RONDINELLI, R. C. Gerenciamento arquivístico de documentos eletrônicos: uma abordagem teórica da diplomática arquivística contemporânea. 4. ed. Rio de Janeiro: FGV, 2005. 160p.

SANTOS, V. B. dos. Gestão de documentos eletrônicos: uma visão arquivística. 2. ed. Brasília: ABARQ, 2005. 223p.

UNIVERSIDADE FEDERAL DE SANTA MARIA. Sistema de Informações para o Ensino: banco de dados. 